\title{
Um relato de experiência sobre interações entre a Ciência e as Artes Visuais na Educação Básica
}

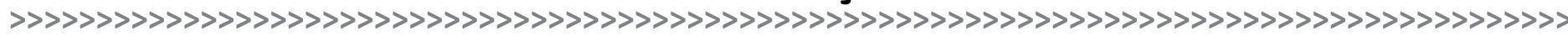

\author{
Josmael Corso* \\ Michel Zózimo da Rocha** \\ Rosane Nunes Garcia***
}

\section{Resumo:}

Um desafio permanente no ensino e na aprendizagem é fornecer conhecimentos que se relacionam entre si e com o cotidiano. Uma das formas de integrar saberes nasce nos momentos em que lúdico e teoria se encontram por meio da interdisciplinaridade. Nessa proposta, relatamos uma experiência interdisciplinar entre conteúdos de evolução biológica e de Artes Visuais. Através do processo que contempla a chamada Alfabetização Científica, os saberes das áreas de conhecimento das Ciências Biológicas e Artes Visuais, realizaram a produção de material educativo: a ilustração da Árvore da Vida. O resultado dessa ação foi uma pintura que faz parte do suporte didático para o ensino, disposto no Laboratório de Ciências do Colégio de Aplicação (CAp-UFRGS). Atividades como a desenvolvida visam a estimular que mais saberes possam se integrar e contribuir com ensino e a aprendizagem de estudantes e professores.

\section{Palavras-chave:}

Interdisciplinaridade. Alfabetização Científica. Ensino das Ciências da Natureza. Artes Visuais. Árvore da Vida.

\section{Resumen:}

Un desafío permanente en la enseñanza y en el aprendizaje es proporcionar conocimientos que se relacionan entre sí y con lo cotidiano. Una de las formas de integrar saberes nace en los momentos en que el lúdico y la teoría se encuentran por medio de la interdisciplinariedad. En esta propuesta, relatamos una experiencia interdisciplinaria entre contenidos de evolución biológica y de Artes Visuales. A través del proceso que contempla la llamada alfabetización científica, los saberes de las áreas de conocimiento de las Ciencias Biológicas y de las Artes Visuales realizaron la producción de material educativo: la ilustración de un Árbol de la Vida. El resultado de esta acción fue una pintura que forma parte del soporte didáctico para la enseñanza, dispuesto en el laboratorio de ciencias del Colegio de Aplicación (CAp-UFRGS). Actividades como la que se ha desarrollado tienen como objetivo estimular que más conocimientos puedan integrarse y contribuir con la enseñanza y el aprendizaje de estudiantes y profesores.

\section{Palabras clave:}

Interdisciplinariedad. Alfabetización científica. Enseñanza de las Ciencias de la Naturaleza. Artes Visuales. Árbol de la Vida.

* > Doutor em Ciências pela Universidade Federal do Rio Grande do Sul, Professor no Instituto Federal do Rio Grande do Sul - Campus Rolante. E-mail: josmaelcorso@gmail.com.

** > Doutor em Artes Visuais pela Universidade Federal do Rio Grande do Sul, Professor no Departamento de Expressão e Movimento do Colégio de Aplicação da UFRGS E-mail: ideiasquenaoderamcerto@gmail. com.

*** > Doutora em Biologia Animal pela Universidade Federal do Rio Grande do Sul, Professora no Departamento de Ciências Exatas e da Natureza do Colégio de Aplicação da UFRGS. E-mail: rosane.garcia@ufrgs.br. 


\section{Reflexões iniciais}

Um desafio que constantemente acompanha as professoras e os professores da Educação Básica é o "como ensinar". Não menos importante, temos que considerar, também, o "para quê ensinar". Certamente não temos respostas prontas para essas perguntas, mas inúmeros referenciais teóricos vêm indicando caminhos para o melhor ensinar que conduzem ao melhor aprender. Um dos caminhos que nos parece interessante é aquele que aponta para a interdisciplinaridade. Ao trabalharmos de forma interdisciplinar, integramos o conhecimento e damos significados mais amplos que favorecem uma leitura de mundo mais eficiente e transformadora. Segundo Japiassu (1976, p. 32),

[...] a característica central da interdisciplinaridade consiste no fato de que ela incorpora os resultados de várias disciplinas, tomando-lhes de empréstimo esquemas conceituais de análise, a fim de fazê-los integrar, depois de havê-los comparado e julgado (JAPIASSU, 1976, p. 32).

Mas, ao pensarmos em trabalhar de forma interdisciplinar na escola, imediatamente nós nos deparamos com situações que são frequentes, tais como o fato de que a formação docente não nos prepara para isso, e os currículos escolares não abrem espaços para o ensino integrado. Apesar disso, muito tem se pensado e muito tem se produzido em torno de propostas educacionais interdisciplinares. Com o mundo em transformação constante e com os avanços que temos conquistado, vozes surgem em diferentes contextos apontando a importância da interdisciplinaridade na educação e de uma visão mais integrada do conhecimento.

É importante destacar, porém, que não se está advogando pelo fim das disciplinas, ou do conhecimento de especialistas. Pelo contrário, ele é a base para a construção da integração. Morin (2003, p. 115) aponta que

Enfim, o importante não é apenas a idéia de inter- e de transdisciplinaridade. Devemos "ecologizar" as disciplinas, isto é, levar em conta tudo que lhes é contextual, inclusive as condições culturais e sociais, ou seja, ver em que meio elas nascem, levantam problemas, ficam esclerosadas e transformam-se. É necessário também o "metadisciplinar"; o termo "meta" significando ultrapassar e conservar. Não se pode demolir o que as disciplinas criaram; não se pode romper todo o fechamento: há o problema da disciplina, o problema da ciência, bem como o problema da vida; é preciso que uma disciplina seja, ao mesmo tempo, aberta e fechada (MORIN, 2003, p. 115).

Os desafios para estabelecermos este processo de abrirmos as fronteiras disciplinares, sem perdermos a identidade de cada campo do conhecimento, são grandes. Mas, através de vivências, estudos, experiências que se compartilham, caminhos podem ser construídos para a superação das dificuldades.

O presente relato de experiência apresenta uma atividade interdisciplinar que nasce a partir do desejo de melhor ensinar conteúdos de evolução biológica e conteúdos de Artes Visuais de forma integrada, além de também desenvolver a Alfabetização Científica. Não é novidade que a Ciência e a Arte são antigas companheiras. Entretanto, ao apresentarmos este relato de experiência, pretendemos colaborar com as professoras e com os professores, no sentido de mostrar possíveis caminhos que possamos trilhar, na busca de um ensino de qualidade nas diferentes áreas do conhecimento. 


\section{Os desafios do ensino de evolução na Educação Básica}

A abordagem da Teoria da Evolução Biológica tem sido amplamente documentada como uma dificuldade de ensino e de aprendizagem na educação escolar (ARAÚJO, 2017; OLEQUES, 2011; MEGLIORATTI, 2005). Entre as diversas implicações para a apropriação deste saber está a compreensão conceitual da Teoria da Evolução Biológica. A própria palavra "evolução" adquire significados diferentes de acordo com as áreas do conhecimento. O senso comum faz uso da ideia de evolução como 'ato de evoluir' para um processo de melhoria. Esse uso é amplamente empregado para explicações relativas ao desenvolvimento histórico de um saber ou de uma tecnologia, como evolução dos telefones celulares, da economia brasileira, dos índices de analfabetismo, entre outros. Games populares, como Pokémon, também se equivocam no uso da expressão evolução para seus ficcionais seres, no qual o termo conceitual correto para o processo vivenciado aos personagens seria metamorfose. A fim de evitar esse primeiro equívoco, no ensino de Biologia, tem se empregado o uso do termo "evolução biológica", para definir o processo de descendência com modificação que ocorre nos seres vivos ao longo do tempo.

Muitas vezes, outro conflito conceitual é a palavra "teoria" que vem sendo utilizada pelos movimentos criacionistas como uma forma de relativizar a compreensão da evolução biológica afirmando que a "evolução é só uma teoria" gerando uma concepção de 'achismo', que ao chegar em público leigo soa como uma explicação razoável, retirando o entendimento factual do processo. No entanto, uma "teoria" científica visa a explicar as observações que são coletadas durante o processo científico, consistindo de uma ou mais hipóteses que foram suportadas em testes repetitivos, que irá corresponder a um conjunto de conhecimentos que explica um determinado fenômeno ou fato (POPPER, 2013). Demais dificuldades na apropriação dos conhecimentos de evolução biológica passam além do tratamento superficial ou equivocado dos conceitos de evolução (DALAPICOLLA, 2015), mas demandam de professores o enfrentamento de questões filosóficas, éticas, ideológicas, religiosas e políticas, as quais não se sentem preparados para tratar com os estudantes de Educação Básica (SEPÚLVEDA; EL-HANI, 2009).

Outra grande dificuldade na compreensão é o fato da Evolução Biológica ser um processo contínuo de mudanças ao longo do tempo. Mas que "ao longo do tempo" é esse? Como ele pode ser demonstrado ou compreendido? Nas definições em livros didáticos, esse é um tempo genérico, sem aspectos geológicos e biológicos (BELLINI, 2006). Compreender o tempo subjetivo é uma barreira para visualizar mudanças que ocorreram em seres durante milhares ou milhões de anos. Se é praticamente impossível saber quem foram nossos antepassados de terceira ou quarta geração, quais eram suas características físicas e quais as possuímos, hoje em dia, como seria possível ilustrar os tempos geológicos do surgimento e da diversificação da vida?

Quando a informação desinforma, outras formas de aprender são necessárias. Além dos livros didáticos e de divulgação científica, há uma infinidade de mídias virtuais em que se pode obter informações sobre evolução. Entre excelentes textos sobre o tema, encontram-se também os imensamente equivocados e absurdos (PAZZA, 2005). Uma vez que é crescente e sem fim a troca de busca do conhecimento em livros por sítios na internet, cabe buscar estratégias integradas e interdisciplinares para construção do conhecimento durante as atividades escolares, a fim de discutir e discernir concepções adequadas das equivocadas.

Nesta proposta trazemos o relato de experiência de uma atividade de pintura de uma Árvore da Vida que busca ilustrar de forma gráfica como se estabelece a relação de ancestralidade e parentesco entre os grupos de seres vivos. Nessa demonstração visual, pretende-se contribuir para a percepção da relação evolutiva entre organismos, de modo a 
desconstruir a visão antropocêntrica, assim como se busca estabelecer que essas relações são determinadas pelas mudanças que ocorrem ao longo do tempo.

O ensino e a aprendizagem de evolução biológica são uma preocupação crescente para a comunidade acadêmica mundial. Para tanto, encontrar formas integradoras para ultrapassar as dificuldades na compreensão do tema, como a proposta neste trabalho, traz ludicidade sobre aspectos importantes que podem ser constantemente apresentados nas diversas áreas do conhecimento.

\section{Onde a Arte e a Ciência se encontram?}

Inúmeros são os pontos de contato entre arte e ciência. Eles remontam aos tempos antigos, quando os campos de conhecimento se confundiam. A ideia de projeção de um futuro imaginado, a invenção de mundos dados pelas lendas, a magia dos antigos, os primeiros desenhos de estrelas, a produção de tintas, os projetos de casas, de mobiliários, de máquinas, de ferramentas, de estradas e pontes.

Exemplificando, os estudos artísticos de corpos humanos utilizando cadáveres, quando as instituições católicas consideravam sacrilégio, resultaram em importantes contribuições que a arte deixou para o campo da saúde. Há incontáveis avanços e descobertas decorrentes de pesquisas que nasceram de processos investigativos dentro do campo artístico, em um tempo em que alquimia, arte e magia antecediam a ideia de Ciência. No interior da história do conhecimento, o processo de separação de seus campos levou à rasa noção de que a Arte e a Ciência ocupariam polos opostos, afastando a razão da sensibilidade, o sensível do concreto, o real do imaginário, a vida do sonho.

É necessário ressaltar que as divisões dos campos de conhecimento e a imposição de suas disciplinas possuem, no seu interior, a lógica de utilidade. Se pensarmos que o útil é aquilo que serve para alguma coisa, que está em função de algo e que faz o mundo funcionar, a Arte não terá relevância nas divisões das disciplinas, ocupando um papel secundário na ordem de importância das coisas. Ao mesmo tempo, paradoxalmente, será onde a palavra escrita não alcança que a Arte voltará a estabelecer seus pontos de contato com a Ciência.

Desde o Iluminismo, utilizando tipos móveis e processos de gravação de imagens, a ideia de reproduzir o conhecimento humano caminhava junto com a lógica reprodutiva do livro, em que, conforme Jacques Rancière (2012, p. 25), se pôde:

[...] construir em torno dos produtos comerciais um halo de palavras e imagens que os tornam desejáveis; reunir graças às prensas mecânicas e ao novo procedimento da litografia, uma enciclopédia do patrimônio humano comum: formas de vida distantes, obras de arte, conhecimentos popularizados (RANCIÈRE, 2012, p. 25).

Não obstante, podemos inferir que a relevância do papel da ilustração, frente ao panorama científico do século XVIII, foi a de contribuir para a proliferação de tecnologias manuais das mais diversas formas possíveis, as quais, na época da edição da Encycloplédie, de Diderot e d'Alembert, não eram amplamente conhecidas. A impossibilidade de explicar precisamente como funcionavam certas coisas ou como alguns trabalhos manuais eram arquitetados, talvez, tenha sido a principal causa responsável pelo uso da ilustração na Enciclopédia, de Diderot e d'Alembert, como aponta Richard Sennett (2009, p. 109-110): "A solução encontrada, em alguns casos, foi substituir palavras por imagens apresentando todo o processo manual do artesão com muitas pranchas impressas".

Como veículo sistematizador e difusor do conhecimento, no século XVIII, foi lançado um grande número de publicações de caráter didático, entre as quais podemos notar a presença marcante da ilustração como modelo didático: Histoire naturelle, générale 
et particulière, de Buffon, e Hortus Botanicus Vindobonensis, de Freiherr von Jacquin. Todavia, será com a Encyclopédie, de Diderot e d'Alembert, que a ilustração científica encontrará o seu ápice na forma de um minucioso, trabalho de produção e seleção iconográficas, como afirma Emanuel Araújo (1986, p. 507), onde, em um total de 35 volumes in-folio, "[...] 12 deles se dedicavam exclusivamente às ilustrações".

Nessa perspectiva, a noção de ilustração poderia ser articulada com a ideia de tradução, a qual auxiliaria os modos de apreensão de determinados assuntos. É muito provável que a proliferação de publicações de divulgação científica e a disseminação de certos conteúdos em meios não especializados seja uma forte consequência, além da linguagem textual acessível, do uso de ilustrações. Aqui, essas duas ferramentas, texto e imagem, desempenham o papel de agentes didáticos, lembrando que o significado de tradução pode carregar consigo a tarefa de acessar, com uma linguagem que nos é familiar, aquilo que nos seus códigos originais pode ser mais complexo, inacessível ou desconhecido.

Nas palavras de Richard Sennett (2009, p. 111), o papel da ilustração na Enciclopédia talvez aponte para a seguinte constatação: "[...] o que somos capazes de dizer em palavras pode ser mais limitado que aquilo que fazemos com as coisas". Ou como nos aponta o pesquisador Gustavo Bernardo (2010, p. 11), a linguagem escrita pode entrar em choque com algumas barreiras invisíveis:

Falo para entender ou comunicar, mas quando o faço provoco sucessivos mal-entendidos. Toda linguagem é simultaneamente pletórica e insuficiente: falo mais do que queria e menos do que devia. Uso a palavra para ter acesso à coisa, mas a palavra me afasta da coisa em si. Como a palavra não me basta por mais que me esforce, preciso ir além dela e explicá-la [...] (BERNARDO, 2010, p. 11).

A ilustração científica é, portanto, uma linguagem gráfica que articula Arte e Ciência, tendo como principal função o papel de agente de comunicação. Na produção e divulgação de conhecimento, a ilustração científica funciona como um registro visual didático-pedagógico que ressalta as principais características dos objetos retratados. $\mathrm{O}$ aprimoramento visual e detalhado que a ilustração científica ganhou ao longo dos séculos fez com que o simbólico deixasse de ser aparente nos desenhos e nas gravuras científicas. Entre inúmeras formas de aprendermos o mundo natural que nos rodeia, a ilustração científica consegue estabelecer uma relação simbiótica entre Arte e Ciência, evidenciando que sua relevância é fundamental nas transformações de tais campos.

\section{Articulando Alfabetização Científica, Artes Visuais e ensino das Ciências da Natureza}

O ensino de conceitos/conteúdos relacionados às Ciências da Natureza tem sido alvo de inúmeras pesquisas e debates, na busca de compreender as melhores formas de desenvolver aprendizagens. Uma das linhas de pensamento que tem se desenvolvido desde a década de 50 do século passado é o ensino das Ciências pautado pelo desenvolvimento da Alfabetização Científica.

O termo Alfabetização Científica foi empregado pela primeira vez por Paul Hurd, no artigo intitulado Science literacy: its meaning to American schools (HURD, 1958) e, a partir deste, há vários estudos que discutem diferentes concepções de Alfabetização Científica têm sido publicados (LAUGKSCH, 2000; SASSERON; CARVALHO, 2011). Em um artigo de revisão, Sasseron e Carvalho (2011) citam diferentes autores e agrupam as habilidades que devem ser desenvolvidas para os indivíduos serem considerados alfabetizados cientificamente, em três blocos ou Eixos Estruturantes da Alfabetização Científica: 
O primeiro desses três eixos estruturantes refere-se à compreensão básica de termos, conhecimentos e conceitos científicos fundamentais e concerne na possibilidade de trabalhar com os alunos a construção de conhecimentos científicos necessários para que seja possível a eles aplicá-los em situações diversas e de modo apropriado em seu dia-a-dia. [...]

O segundo eixo preocupa-se com a compreensão da natureza das ciências e dos fatores éticos e políticos que circundam sua prática. Reporta-se, pois, à ideia de ciência como um corpo de conhecimentos em constantes transformações por meio de processo de aquisição e análise de dados, síntese e decodificação de resultados que originam os saberes. [...]

O terceiro eixo estruturante da AC compreende o entendimento das relações existentes entre ciência, tecnologia, sociedade e meio-ambiente. Trata-se da identificação do entrelaçamento entre estas esferas e, portanto, da consideração de que a solução imediata para um problema em uma destas áreas pode representar, mais tarde, o aparecimento de um outro problema associado. [...] (SASSERON; CARVALHO, 2011, p. 75, grifos nossos)

As autoras consideram que as propostas didáticas que surgirem respeitando esses três eixos devem ser capazes de promover o início da Alfabetização Científica, pois terão criado oportunidades para trabalhar problemas envolvendo a sociedade e o ambiente, discutindo, concomitantemente, os fenômenos do mundo natural associados, a construção do entendimento sobre esses fenômenos e os empreendimentos gerados a partir de tal conhecimento (SASSERON; CARVALHO, 2011).

Ao estudarmos fenômenos naturais em uma perspectiva interdisciplinar em que a Arte desenvolve aprendizagens relacionadas à sensibilidade e à observação, torna possível qualificar o ensino das Ciências da Natureza, e por consequência, favorecer o desenvolvimento da Alfabetização Científica. Cachapuz (2014, p. 105) diz que:

A questão interessante é, no quadro de uma visão não redutora e não segmentada do conhecimento, quais as semelhanças que as unem e de que modo tal visão diacrónica Arte/Ciência pode melhorar a qualidade da educação em ciências oferecida aos alunos e dar uma oportunidade aos professores para irem mais além das rotinas e burocracia a que frequentemente são submetidos nas suas escolas (CACHAPUZ, 2014, p. 105).

No mesmo artigo, Cachapuz (2014) apresenta possibilidades da interação entre Arte e Ciência com o uso de poemas, pinturas, obras cinematográficas, favorecendo, dessa forma, o desenvolvimento da sensibilidade, “[...] fugindo dos limites da racionalidade positivista da Ciência" (CACHAPUZ, 2014, p. 102).

\section{A Árvore da Vida - o relato da experiência}

O Colégio de Aplicação (CAp) da UFRGS é uma escola de Educação Básica que atende estudantes desde o primeiro ano do Ensino Fundamental até a Educação de Jovens e Adultos. A escola está sediada no Campus do Vale e dispõe de três prédios, com salas de aula e laboratórios, além de quadras para esportes, um teatro, salas para aulas de música e de Artes Visuais.

Um dos ambientes disponíveis é o laboratório de ciências que apresenta um espaço amplo estruturado com diferentes materiais, animais fixados, vidrarias, além de reagentes que podem ser utilizados em aulas de Química. Há seis anos, as áreas de Biologia e de Química vêm desenvolvendo projetos de trabalho interdisciplinar e frequentemente utilizam o laboratório para atividades de aulas práticas ou teórico-práticas. 
No ano de 2016, iniciou-se um projeto que pretendia organizar melhor as coleções de seres vivos do laboratório, além de desenvolver materiais pedagógicos que auxiliassem nas aulas. Nesse processo nasceu a ideia da construção de recursos visuais, especificamente pinturas nas paredes do laboratório realizadas pelos estudantes, que estivessem permanentemente disponíveis para as aulas, além de, também serem uma importante forma de expressão que valorizaria a integração entre a Arte e a Ciência. Ao envolvermos estudantes no processo de elaboração e construção do material, estariam sendo desenvolvidas aprendizagens importantes de conteúdos mais amplos e em uma perspectiva integrada entre as Artes Visuais e a Biologia.

Um dado que merece ser ressaltado, nas aulas de Artes Visuais das turmas de $9^{\circ}$ ano do Ensino Fundamental (no Colégio de Aplicação, as turmas de $8^{\circ}$ e $9^{\circ}$ anos fazem parte do Projeto de Ensino Pixel), é o desejo recorrente de certos alunos por diferentes abordagens e aplicações da linguagem gráfica do desenho. Entre elas, a ilustração científica merece destaque como uma demanda de interesse que surge dos próprios alunos de Artes Visuais. Portanto, as técnicas de realização de ilustrações científicas, tais como claro e escuro, luz e sombra, textura, padrão e repetição são sempre trabalhadas nas aulas de Artes Visuais. No entanto, com esta proposta, a aplicação da ilustração científica passa a fazer parte também do processo investigativo que envolve a produção de conteúdo estético com função pedagógica.

Para viabilizar a ação da produção de material pedagógico integrando Ciência e Artes Visuais, foi organizada a participação dos estudantes através de um projeto, em que, além de elaborar a pintura, todos deveriam desenvolver a sua pesquisa sob orientação dos professores, alinhada à temática Arte e Ciência. A primeira proposta para iniciar a produção dos materiais foi a realização de uma pintura na parede do Laboratório de Ciências de uma Árvore da Vida, na qual seria representada a figura de uma árvore, com ramos e, na ponta dos ramos, estariam os principais representantes de grupos de seres vivos, de acordo com a Teoria da Evolução Biológica.

Entre as diversas contribuições de Alfred Wallace e Charles Darwin para o conhecimento evolutivo, talvez a maior seja a ideia de que todos os seres vivos apresentam uma relação histórica de ancestralidade comum que pode ser graficamente representada na forma de uma árvore (AMORIM, 2002). A Árvore da Vida tem como princípio organizar toda a vida conhecida pela Ciência, incluindo organismos extintos, de modo a visualizar, de forma mais simples, a relação de todos estes com o mais antigo ancestral comum universal (Last Universal Common Ancestor, ou LUCA), que seria o último organismo do qual todos os demais descendem (SANTOS, 2019). Desse modo, a presente proposta de trazer para o espaço didático do laboratório de Ciências uma ilustração da Árvore da Vida, contribui para aproximar os alunos da percepção da relação de parentesco entre os organismos.

Antes da etapa da pintura na parede do laboratório, ocorreu um preparo das estudantes com a realização de atividades mais direcionadas, em que foram estabelecidos ajustes no traçado, nas cores, escolha das figuras e do material. Tudo era registrado em um "caderno de artista" (Figura 1). 
Figura 1 - Desenho de autoria da estudante do Ensino Médio, Sheron Roberta das Neves Sassaro no "caderno de artista".

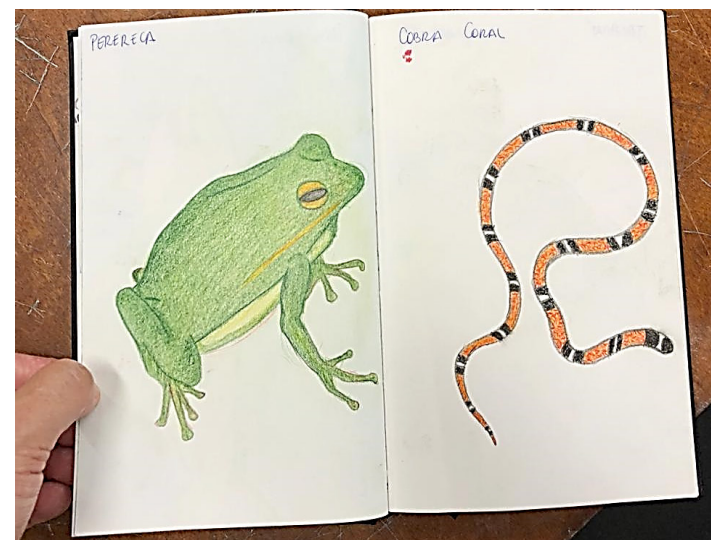

Fonte: Os autores

Após a etapa preparatória, semanalmente, no contraturno das aulas, professores orientadores e estudantes passaram a se reunir para fazer a pintura na parede do laboratório (Figuras 2, 3, 4 e 5), além de realizarem estudos, leituras, diálogos e atividades relacionadas ao trabalho artístico, assim como o desenvolvimento das suas pesquisas individuais.

Figuras 2, 3, 4 e 5 - Pintura da Árvore da Vida em processo de elaboração em uma das paredes do laboratório de Ciências do Colégio de Aplicação da UFRGS. As figuras 4 e 5 mostram em detalhe algumas imagens produzidas pelas estudantes. Atualmente o projeto conta com a participação de quatro bolsistas do Programa de Bolsas Primeira Ciência (PBPC) UFRGS/CNPq, todas estudantes do Ensino Médio: Sheron Roberta das Neves Sassaro, Franciele dos Santos Vaz, Giovana Lírio da Rocha e Isabella Borges Gonzaga.

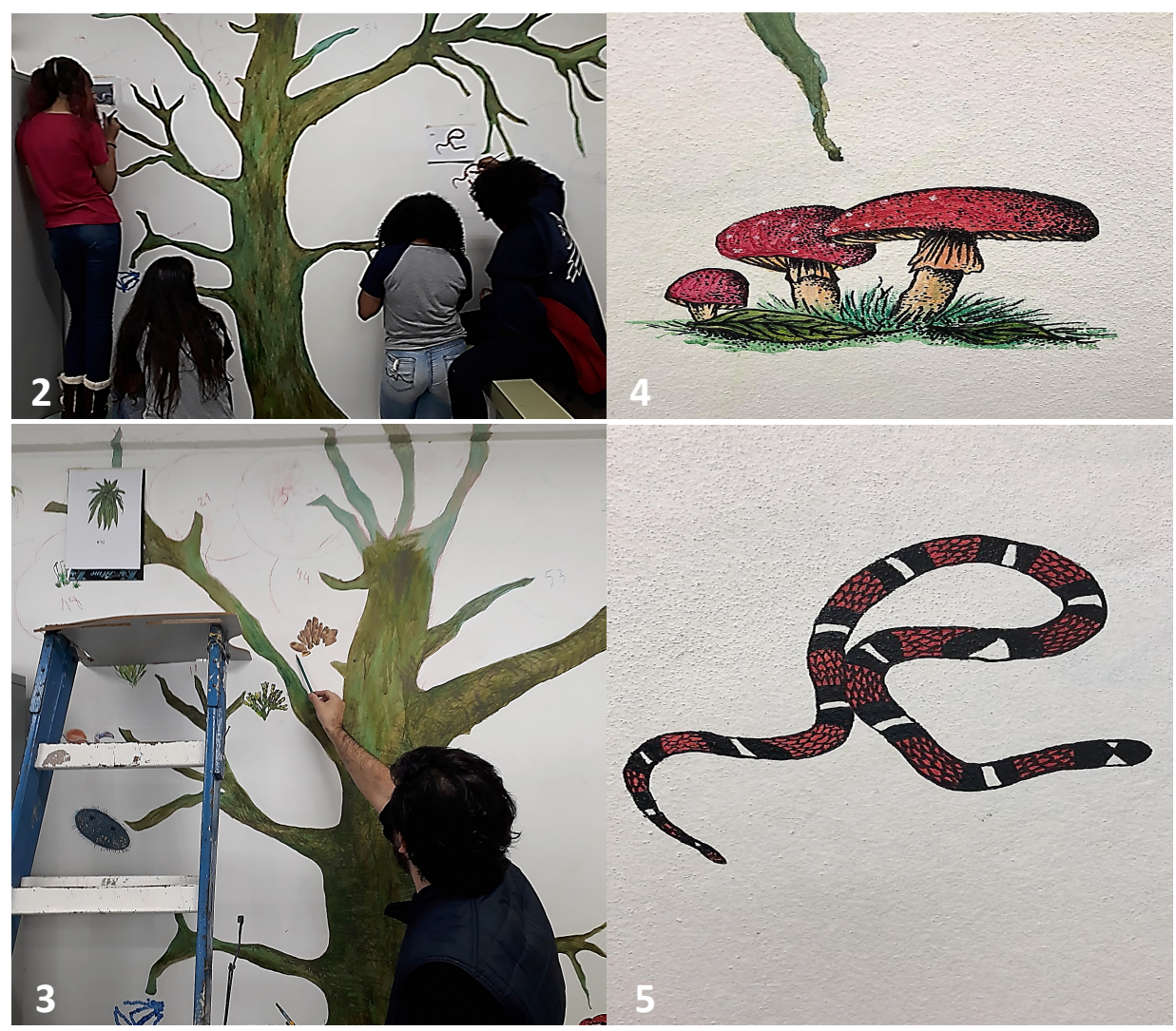

Fonte: Os autores 
O que se percebe com o desenvolvimento dessas atividades é que as estudantes se mostram muito envolvidas, estabelecem relações e ressignificam o conhecimento científico, quando associam os diferentes campos do conhecimento nesta proposta.

\section{Reflexões finais}

Iniciativas na escola que promovam a interdisciplinaridade são importantes, e acreditamos que, ao trabalharmos os conceitos das Ciências da Natureza integrados com a Arte, além de promovermos a Alfabetização Científica, estamos possibilitando também o desenvolvimento de aprendizagens mais contextualizadas, ampliando a possibilidade dos estudantes estabelecerem relações significativas entre diferentes campos do conhecimento.

Assim, entendemos que o projeto que envolve, entre outras atividades, a pintura da Árvore da Vida, que vem sendo desenvolvido com um grupo de estudantes da Educação Básica do Colégio de Aplicação da UFRGS, tem um caráter interdisciplinar por integrar os conhecimentos de dois componentes curriculares distintos para a produção de material pedagógico, favorecendo, dessa forma, a construção de um saber escolar que permite desenvolver uma visão mais complexa e crítica de mundo.

Consideramos ainda que o desenvolvimento da Alfabetização Científica é favorecido em projetos como o apresentado neste relato de experiência, pois possibilita que as estudantes compreendam termos e conceitos relacionados aos conhecimentos científicos, neste caso, os conceitos relacionados à evolução biológica. Também permite a compreensão da natureza da Ciência, devido ao fato de que, além do projeto de pesquisa individual desenvolvem na temática Arte e Ciência, ao longo do processo de pintura da árvore são feitas leituras e rodadas de reflexões a respeito das descobertas científicas e os contextos histórico-culturais em que se estabelecem, assim como das relações entre a Arte e a Ciência, explorando como os saberes destes campos de conhecimento foram se constituindo e se e se modificando ao longo da atividade. Por fim, o reconhecimento por parte das estudantes a respeito dos debates historicamente registrados em torno dos saberes construídos pelos evolucionistas em diferentes épocas, leva ao entendimento sobre o impacto dos conhecimentos científicos na sociedade.

\section{Referências}

AMORIM, Dalton de Souza. Fundamentos de sistemática filogenética. Ribeirão Preto: Holos Editora, 2002.

ARAÚJO, Emanuel. A construção do livro. Rio de Janeiro: Nova Fronteira, 1986.

ARAÚJO, Leonardo Augusto Luvison (org.). Evolução biológica: da pesquisa ao ensino. Porto Alegre: Fi, 2017.

BELLINI, Marta L. O conceito de evolução nos livros didáticos: avaliação metodológica. Estudos em Avaliação Educacional, v. 33, p. 7-28, 2006.

BERNARDO, Gustavo. O livro da metaficção. Rio de Janeiro: Tinta Negra, 2010.

CACHAPUZ, Antonio Francisco. Arte e Ciência no ensino das ciências. Interacções, n. 31, p. 95-106, 2014. Disponível em: https://revistas.rcaap.pt/interaccoes/article/view/6372/4941. Acesso em: 30 abr. 2019.

DALAPICOLLA, Jeronymo; SILVA, Victor de Almeida; GARCIA, Junia Freguglia Machado. Evolução Biológica como eixo integrador da biologia em livros didáticos do ensino médio. Ensaio Pesquisa em Educação em Ciências, Belo Horizonte, v. 17, n. 1, p. 150-173, 2015.

JAPIASSU, Hilton. Interdisciplinaridade e patologia do saber. Rio de Janeiro: Imago Editora LTDA, 1976. 
LAUGKSCH, Rüdiger. Scientific Literacy: A conceptual overview. Science Education, v. 84, p. 71-94, 2000.

MEGLIORATTI, Fernanda Aparecida. História da Biologia: aproximações possíveis entre categorias históricas e concepções sobre ciência e evolução apresentadas pelos professores de biologia. p. 11-28. In: CALDEIRA, Ana Maria de Andrade; CALUZI, João José (orgs.). Filosofia e história da ciência: contribuições para o ensino de ciência. Ribeirão Preto: Kayrós, 2005.

MORIN, Edgar. A cabeça bem-feita: repensar a reforma, reformar o pensamento. Rio de Janeiro: Bertrand Brasil, 2003.

OLEQUES, Luciane Carvalho; BARTHOLOMEI-SANTOS, Marlise Ladvocat; BOER, Noemi. Evolução biológica: percepções de professores de biologia. Revista Electrónica de Enseñanza de las Ciencias, Vigo, v. 10, p. 243-264, 2011.

PAZZA, Rubens. Aproveitadores de deslizes no jornalismo científico. Jornal da Ciência e-mail, SBPC, 10 maio 2005.

RANCIÈRE, Jacques. O destino das imagens. Rio de Janeiro: Contraponto, 2012.

SANTOS, Wesley. Do Nano ao Macro. Árvore da Vida. Disponível em: http://www.nano-macro. com/2012/07/arvore-da-vida.html. Acesso em: 27 mar. 2019.

SASSERON, Lúcia Helena; CARVALHO, Anna Maria Pessoa. Alfabetização científica: uma revisão bibliográfica. Investigação em Ensino de Ciências, v. 16, n. 1, p. 59-77, 2011.

SENNET, Richard. O artífice. Rio de Janeiro: Record, 2009.

SEPULVEDA, Cláudia; EL-HANI, Charbel. Niño. Ensino de Evolução: uma experiência na formação inicial de professores de biologia. In: TEIXEIRA, Paulo Marcelo Marini; RAZERA, Júlio César Castilho (orgs.). Ensino de Ciências: pesquisas e pontos em discussão. Campinas: Komedi, 2009. 